\title{
Ant Mutualism Increases Long-Term Growth and Survival of a Common Amazonian Tree
}

\author{
Selene Báez, ${ }^{1, \star}$ David A. Donoso, ${ }^{1,2}$ Simon A. Queenborough, ${ }^{3}$ Liliana Jaramillo, ${ }^{4}$ \\ Renato Valencia, ${ }^{4}$ and Olivier Dangles ${ }^{5}$
}

1. Museo de Colecciones Biológicas, Universidad Técnica Particular de Loja, Loja, Ecuador; 2. Instituto de Ciencias Biológicas, Escuela Politécnica Nacional, Avenida Ladrón de Guevara E11-253, Quito, Ecuador; 3. Yale School of Forestry and Environmental Studies, Yale University, New Haven, Connecticut; 4. Laboratorio de Ecología de Plantas, Herbario QCA, Escuela de Ciencias Biológicas, Pontificia Universidad Católica del Ecuador, Quito, Ecuador; 5. Institut de Recherche pour le Développement, Unité Mixte de Recherche EGCE (Laboratoire Evolution, Génomes, Comportement, Ecologie), Université Paris-Saclay, Campus Centre National de la Recherche Scientifique, Gif-sur-Yvette Cedex, France; and Facultad de Ciencias Exactas y Naturales, Pontificia Universidad Católica del Ecuador, Quito, Ecuador

Submitted January 18, 2016; Accepted May 17, 2016; Electronically published August 30, 2016

Online enhancements: appendix. Dryad data: http://dx.doi.org/10.5061/dryad.42p15.

\begin{abstract}
How ecological context shapes mutualistic relationships remains poorly understood. We combined long-term tree census data with ant censuses in a permanent 25-ha Amazonian forest dynamics plot to evaluate the effect of the mutualistic ant Myrmelachista schumanni (Formicinae) on the growth and survival of the common Amazonian tree Duroia hirsuta (Rubiaceae), considering its interactions with tree growth, population structure, and habitat. We found that the mutualist ant more than doubled tree relative growth rates and increased odds of survival. However, host tree size and density of conspecific neighbors modified the effect of the ant. Smaller trees hosting the mutualist ant consistently grew faster when surrounded by higher densities of conspecifics, suggesting that the benefit to the tree outweighs any negative effects of high conspecific densities. Moreover, our findings suggest that the benefit afforded by the ant diminishes with plant age and also depends on the density of conspecific neighbors. We provide the first long-term large-scale evidence of how mutualism affects the population biology of an Amazonian tree species.
\end{abstract}

Keywords: age-structured populations, ant-plant interactions, Duroia hirsuta, mutualism, Myrmelachista schumanni, ontogeny.

\section{Introduction}

It is broadly recognized that ant-plants are generally well protected by their mutualist partners: ants provide protection from herbivores, increase nutrient availability, and promote seed dispersal of ant-plants (Mayer et al. 2014). However, to what extent ant protection translates into higher perfor-

\footnotetext{
* Corresponding author; e-mail: selenebae@gmail.com. ORCIDs: Báez, http://orcid.org/0000-0002-7236-6242; Jaramillo, http://orcid.org /0000-0002-8611-8311; Donoso, http://orcid.org/0000-0002-3408-1457.
}

Am. Nat. 2016. Vol. 188, pp. 1-9. (C) 2016 by The University of Chicago. 0003-0147/2016/18804-56749\$15.00. All rights reserved. DOI: $10.1086 / 688401$ mance and thereby higher fitness of the plant is less clear (Chamberlain and Holland 2009; Rosumek et al. 2009; Trager et al. 2010). For example, among myrmecophytic tropical trees there is strong evidence that the benefit conferred by mutualist ants to their host plants varies strongly, depending on the ecological context (i.e., local biotic and environmental neighborhoods; Bronstein 1994; Bronstein et al. 2006). Indeed, long-lived tropical trees may even experience reduced growth rates because of the high costs of maintaining mutualist ants (Stanton and Palmer 2011; Frederickson et al. 2012). Because growth is tightly linked to survival and fitness, hosting a mutualist partner may not necessarily result in substantial net benefits for these trees (Stanton and Palmer 2011; Lange and Del-Claro 2014). Assessing the longterm net benefits of mutualism on plant performance and fitness therefore requires careful quantification of associated biotic and abiotic covariates alongside the mutualism itself.

Over the long term, plant ontogeny may determine the relative importance of direct and indirect defense and the benefit afforded by different mutualist partners. In general, ant-plants seem to be better protected by their mutualist partners as they age (Boege and Marquis 2005), and older plants may host more aggressive types of mutualist ants (Koch et al. 2016). Indeed, various species of Amazonian trees have size-dependent interactions with their mutualistic partners. For example, the interaction between Duroia hirsuta and Myrmelachista schumanni ants may result in positive size-dependent growth for both mutualistic partners as larger trees exhibit exponential growth rates (Fred erickson and Gordon 2009). African Acacia trees have different ant partners throughout ontogeny, trading off the costs and benefits associated with each type of partnership (Palmer et al. 2010). Thus, understanding ant-plant sys- 
tems requires long-term field assessments that consider the effects of mutualism on ant-plants at different ontogenic stages.

Feedbacks resulting from the effect of the mutualist ant on plant performance can affect plant population demography. To maintain the mutualism, both ants and plants must benefit in terms not only of performance of individuals but also of increased fitness and maintained or growing populations. Over long periods of time, mutualism may enhance population growth rates of myrmecophytic trees. For example, in highly diverse Amazonian forests, monospecific stands of the tree $D$. hirsuta result from its mutualistic interaction with the ant M. schumanni, which kills non-D. hirsuta seedlings and enhances recruitment rates of new $D$. hirsuta trees into the ant-plant populations (Frederickson 2005b; Edwards et al. 2009). Myrmelachista schumanni may also increase the probability of survival of D. hirsuta trees (Frederickson and Gordon 2009). However, high population densities of ant-plants may reach a plateau of growth because of negative density dependence (NDD; Wright 2002) and herbivory or pathogen attack (Frederickson and Gordon 2007; Comita et al. 2014). Therefore, both ontogenic stage and density of neighboring ant-plants may be important controllers of the effect of the mutualist ant on any individual ant-plant (Miller and Rudolf 2011). Depending on the age structure of the population, the influence of the mutualist ant on ant-plants can have strong effects at the population scale (Miller and Rudolf 2011).

Moreover, mutualistic relationships between ants and plants are often shaped by environmental conditions. Plant investment in biotic defense may vary with aspects of the environment, including light incidence, soil moisture, and nutrient availability. For example, high light availability increases ant protection against herbivory in Inga vera (Kersch and Fonseca 2005). Higher soil nutrient availability and moisture enhance the production of food rewards, which increases ant densities and results in improved protection of the tree Macaranga triloba (Heil et al. 2002). Improved light and soil nutrient conditions enhance the production of food rewards for mutualist ants in Cecropia spp., enhancing ant protection to the plant (Folgarait and Davidson 1995). In tropical rain forests, soil nutrient concentrations, soil moisture, and light incidence tend to covary with habitat (Tuomisto et al. 2003; John et al. 2007). Thus, environmental heterogeneity across habitats may affect the mutualism between ants and plants, as ant-plants in certain habitats may experience greater long-term benefits from a given mutualist partner.

Building a more complete picture of the effects of ant mutualism on plant performance and fitness therefore requires estimating the balance between the positive and negative effects of tree size (as a proxy for ontogenic variation) and habitat on focal plants, along with their interaction with the mutualist ant. This information would allow us to infer how mutualism affects the demography of agestructured populations (Miller and Rudolf 2011). Assessing critical aspects of the performance, including growth and survival, of large and long-lived organisms requires monitoring substantial numbers of individuals over large spatial and temporal scales. Permanent forest dynamics plots offer a unique opportunity to investigate these questions, which are of particular relevance in species-rich and ecologically complex tropical systems. In this article, we explore how mutualism, ontogeny, density of conspecifics, and habitat affected the growth and survival of $334 \mathrm{D}$. hirsuta trees over 18 years in a 25-ha permanent Amazonian lowland forest. We investigated the following hypotheses: (1) ant mutualism has a beneficial effect on the short- and long-term growth and survival of D. hirsuta; (2) however, the effect of mutualistic ants on plant performance varies according to host tree ontogeny, density of conspecifics, and habitat, with greater benefit experienced by larger trees with few conspecific neighbors in resource-rich environments.

\section{Material and Methods}

$$
\text { Study Site }
$$

The study was conducted in the Yasuní National Park and Biosphere Reserve in eastern Amazonian Ecuador. Yasuní has an aseasonal climate, with a mean monthly temperature of $25^{\circ} \mathrm{C}$ and annual precipitation rates of about $3,000 \mathrm{~mm}$ (Pérez et al. 2014). This evergreen lowland rain forest is recognized worldwide for having extremely high biological diversity (Bass et al. 2010). The study was conducted in a 25-ha permanent forest dynamics plot (latitude $0.69^{\circ} \mathrm{S}$, longitude $76.39^{\circ} \mathrm{W}$; Valencia et al. 2004; Pérez et al. 2014). The plot lies at $230 \mathrm{~m}$ above sea level, and within the plot there is variation in elevation of $33.5 \mathrm{~m}$. All tree stems at least $1 \mathrm{~cm}$ in diameter at breast height ( $\mathrm{DBH}$; breast height is $1.3 \mathrm{~m}$ ) have been mapped, identified, and measured with standard methods every 5 years since 1995 (Valencia et al. 2009; Pérez et al. 2014).

\section{Study System}

The tropical tree Duroia hirsuta K. Schum. (Rubiaceae) is a subcanopy tropical tree that frequently forms monospecific stands in Amazonian rain forests known as "devil's gardens," or supay chakras in the native Quichua language (Frederickson 2005b). Duroia hirsuta's domatia (hollow stems) shelter hemipteran coccoids, which provide honeydew to symbiotic ants. Most frequently, $D$. hirsuta hosts colonies of the mutualistic, polygynous ant Myrmelachista schumanni Emery (Formicinae), although other ant species in the genera Azteca, Brachymyrmex, Pheidole, and Solenopsis may also 
be present. Myrmelachista schumanni affords various types of benefits to its host trees. This mutualist ant protects D. hirsuta from herbivore attack, clears neighboring vegetation around ant-plants, and may increase the establishment of new $D$. hirsuta by galling the trunks of heterospecific trees surrounding supay chakras (Frederickson 2005a; Edwards et al. 2009). In our study site, however, none of the 178 heterospecific trees with $\mathrm{DBH} \geq 1 \mathrm{~cm}$ located in eight $10 \times$ 20 -m plots within $20 \mathrm{~m}$ of four supay chakras had gallings due to M. schumanni (S. Báez, unpublished data). Myrmelachista schumanni is the only species of ant associated with $D$. hirsuta that has this understory-clearing behavior (Frederickson 2005b).

Supay chakras vary in size. Studies conducted in Peruvian Amazonia report large monospecific stands of D. hirsuta (mean of 23 individual trees) as well as the largest D. hirsuta aggregation ever recorded, with 594 individuals (Frederickson and Gordon 2009). Stands of D. hirsuta in our study site are smaller, with a maximum of 11 individuals (Jaramillo 2012), but the presence of clearings is still indicative of the presence of M. schumanni. Here, 96\% (in 2010) and 70\% (in 2013) of D. hirsuta hosting M. schumanni had understory clearings. In Peru, colonies of M. schumanni have a life expectancy of 11 years (Frederickson and Gordon 2009), and certain supay chakras have been estimated to be 800 years old (Frederickson 2005b).

\section{Field Surveys}

Tree growth and survival. We used diameter measures of all D. hirsuta with $\mathrm{DBH} \geq 1 \mathrm{~cm}$ taken in 1995,2007 , and 2013. Tree survival was evaluated in 2013 only for trees that were checked for ant clearings (as a proxy of the presence of M. schumanni) in 2010.

Ant mutualism. Mutualistic relations between D. hirsuta and M. schumanni were evaluated through two censuses conducted 3 years apart. In 2010 and 2013, D. hirsuta trees measuring at least $1 \mathrm{~cm} \mathrm{DBH}$ in the 25-ha plot were checked for the presence of M. schumanni in their domatia. When ants were present, these were collected, preserved, and identified. For each tree, understory conditions were classified as "ant clearing," if the understory was reduced in vegetative cover and height, or "closed understory," when there were no signs of reduced cover. In the 2010 census, understory conditions were documented for 213 ant-plants, and 151 individuals chosen randomly were examined for the presence of ants in their domatia. In the 2013 census, all $D$. hirsuta trees with $\mathrm{DBH} \geq 1 \mathrm{~cm}$ (234 individuals) in the 25-ha plot were examined (table 1).

Density of conspecifics. On the basis of tree distribution maps for the Yasuní permanent plot, we measured the number of conspecific neighbors with $\mathrm{DBH} \geq 1 \mathrm{~cm}$ within $5 \mathrm{~m}$ for each D. hirsuta in 1995 and 2007.

Habitat. Elevation and habitat in tropical forests have been shown to correlate with water, light, and soil nutrient availability (Losos and Egbert 2004), including at Yasuní (John et al. 2007; Queenborough et al. 2007). Thus, one of the three main habitats was assigned to each $20 \times 20-\mathrm{m}$ subplot of the permanent plot: ridge, slope, or valley, following Valencia et al. (2004). Each habitat category correlates with environmental features relevant for plant growth; for example, valleys have higher soil nutrient concentrations than slopes and ridges (John et al. 2007).

\section{Data Analysis}

We used generalized linear models to evaluate the relative effect of mutualistic ants on D. hirsuta growth over 6 (2007-2013) and 18 (1995-2013) years, accounting for density of conspecifics and habitat. For the 6-year period, trees that had M. schumanni during both censuses were considered to have hosted the mutualist ant during the entire interval. Given that the life span of ant colonies is longer than 6 years, missed ant turnover was probably very small in our data set. For the 18-year period, D. hirsuta hosting M. schumanni were defined as plants that consistently hosted M. schumanni over the 3-year ant census interval and also presented ant understory clearings in 2010. Thus, these

Table 1: Summary of variables and data included in the statistical models over 6 and 18 years

\begin{tabular}{|c|c|c|c|c|}
\hline \multirow[b]{2}{*}{ Parameter } & \multicolumn{2}{|c|}{ Short term (6 years) } & \multicolumn{2}{|c|}{ Long term (18 years) } \\
\hline & Mean (SD) & Range & Mean (SD) & Range \\
\hline Growth $\left(\mathrm{mm}\right.$ year $\left.{ }^{-1}\right)$ & $.01(.05)$ & -.38 to .26 & $.99(1.21)$ & -2.72 to 4.59 \\
\hline Tree size $(\mathrm{mm})$ & $48.29(22.53)$ & $10-112$ & $46.06(22.62)$ & $11-110$ \\
\hline Density of conspecifics $(n)$ & $1.04(1.45)$ & $0-6$ & $1.14(1.72)$ & $0-7$ \\
\hline Myrmelachista $(n)$ & 88 & $\ldots$ & 84 & $\ldots$ \\
\hline No ant $(n)$ & 146 & $\ldots$ & 136 & $\ldots$ \\
\hline Ridge habitat $(n)$ & 50 & $\ldots$ & 55 & $\cdots$ \\
\hline Slope habitat $(n)$ & 154 & $\ldots$ & 167 & $\ldots$ \\
\hline Valley habitat $(n)$ & 54 & $\ldots$ & 58 & $\ldots$ \\
\hline
\end{tabular}


trees were more likely to have hosted the ant species for a longer time before the first ant census. We calculated individual relative annual tree growth rates as the relative increase in the cross sectional area of the tree, $\left[\left(\mathrm{DBH}_{t 1} / 2\right)^{2}-\right.$ $\left.\left(\mathrm{DBH}_{t 0} / 2\right)^{2}\right] /\left[\left(\mathrm{DBH}_{t 0} / 2\right)^{2} \times(t)\right]$, where $t_{1}$ is the later $\mathrm{DBH}$ measurement, $t_{0}$ is the initial $\mathrm{DBH}$ measurement, and $t$ is the time in years between censuses.

To model tree performance, we used simple linear models to estimate $D$. hirsuta growth rate as a function of ant presence, initial tree size $(\mathrm{DBH}$ in $\mathrm{cm}$ ) as a proxy of tree age, the number of conspecific $D$. hirsuta within $5 \mathrm{~m}$, and habitat (ridge, slope, or valley; table 2). Then, to examine the relative effects of these predictor variables on tree performance, we compared a suite of nested and nonnested multiple-regression models using the Akaike information criterion (AIC) and $R^{2}$ (Burnham and Anderson 2004; Symonds and Moussalli 2011). Models differing by no more than 2 in their AIC values were considered of equal validity.

We used a logistic-regression model to evaluate the relative effect of mutualistic ants on tree survival, testing survival from 2010 to 2013 as a function of ant incidence (presence/ absence of ants), tree size, number of conspecific neighbor trees, and habitat. We used the software JMP (SAS Institute 2008) and R (R Development Core Team 2014) for statistical analyses.

\section{Results}

Plant population. Over the course of this study, we measured growth rates of 314 individual trees. The Duroia hirsuta population decreased over the duration of the study. In 1995 there were $280 \mathrm{D}$. hirsuta trees of at least $1 \mathrm{~cm} \mathrm{DBH}$, and 80 of them died by 2013. Between 1995 and 2013, 34 trees were recruited that reached $\mathrm{DBH} \geq 1 \mathrm{~cm}$. By 2013, the population had 234 individuals.
Ant incidence and dynamics. Myrmelachista schumanni was present in $67 \%$ (101 of 151 individuals) of the trees examined in the 2010 ant census and in 56\% (133 of 234 individuals) of the entire population of D. hirsuta in the 2013 ant census (table 1). Of the $101 \mathrm{D}$. hirsuta that hosted $M$. schumanni in 2010, 11 had lost their mutualistic ant by 2013.

Tree growth rates. As we predicted, over the short term (6 years) the effect of ants was beneficial: D. hirsuta that hosted M. schumanni grew twice as fast as trees that hosted other types of ants or no ants (mean relative growth rate $0.60 \pm 0.18 \mathrm{~mm} \mathrm{year}^{-1}$ for trees with $M$. schumanni vs. $0.28 \pm 0.12 \mathrm{~mm} \mathrm{year}^{-1}$ for trees with other species of ants or no ants; table 1; fig. 1). Trees hosting M. schumanni also grew faster than trees with Azteca sp. (nonparametric Wilcoxon test, $P<.001)$. In addition, tree growth rates declined significantly with increasing initial tree size, but habitat type and density of conspecific trees did not have a statistically significant effect on focal tree growth when modeled as individual simple least squares regressions (fig. 1). Data underlying figure 1 are deposited in the Dryad Digital Repository: http://dx.doi.org/10.5061/dryad.42p15 (Báez et al. 2016).

Over the long term (18 years), presence of the mutualist ant also significantly increased growth rates (fig. 1). Trees with $M$. schumanni and growing in ant clearings grew faster than trees without M. schumanni $\left(0.35 \pm 0.26 \mathrm{~mm} \mathrm{year}^{-1}\right.$ for trees with $M$. schumanni vs. $0.07 \pm 0.21 \mathrm{~mm} \mathrm{year}^{-1}$ without). As with short-term growth, tree growth rate over 18 years decreased with tree size and was not affected by variation in habitat or density of conspecifics when modeled as individual regressions (fig. 1).

When we evaluated the relative effects of all the variables on growth, using AIC and $R^{2}$ values to compare our models, we found that over the short term most variation was explained by the interaction between ant incidence and tree

Table 2: Comparison of nested models exploring growth rates of Duroia hirsuta as a function Myrmelachista schumanni presence (ant), tree size, density of conspecific neighbors, and habitat over 6 and 18 years

\begin{tabular}{|c|c|c|c|c|c|c|}
\hline \multirow[b]{2}{*}{ Model } & \multicolumn{3}{|c|}{ Short term (6 years) } & \multicolumn{3}{|c|}{ Long term (18 years) } \\
\hline & AIC & $\Delta_{\mathrm{AIC}}$ & $R^{2}$ & AIC & $\Delta_{\mathrm{AIC}}$ & $R^{2}$ \\
\hline Ant $\times \mathrm{DBH}$ & 27.22 & .00 & .05 & -163.24 & 8.11 & .24 \\
\hline Ant $\times$ density of conspecifics & 37.72 & 10.50 & .03 & -122.79 & 48.56 & .07 \\
\hline Ant $\times$ habitat & 36.80 & 9.58 & .02 & -115.46 & 55.90 & .05 \\
\hline Ant $\times \mathrm{DBH}+$ habitat & 28.87 & 1.65 & .06 & -161.16 & 10.20 & .25 \\
\hline Ant $\times \mathrm{DBH}+$ density of conspecifics & 29.18 & 1.96 & .05 & -164.66 & 6.70 & .25 \\
\hline Ant $\times \mathrm{DBH}+$ ant $\times$ habitat & 31.31 & 4.09 & .06 & -157.58 & 13.78 & .25 \\
\hline Ant $\times \mathrm{DBH}+$ ant $\times$ density of conspecifics & 31.04 & 3.82 & .05 & -163.65 & 7.71 & .25 \\
\hline Ant $\times \mathrm{DBH}+$ ant $\times$ habitat + density of conspecifics & 30.85 & 3.63 & .06 & -164.48 & 6.88 & .26 \\
\hline Ant $\times \mathrm{DBH}+$ ant $\times$ habitat + ant $\times$ density of conspecifics & 35.08 & 7.86 & .06 & -160.92 & 10.43 & .27 \\
\hline Ant $\times$ DBH $\times$ density of conspecifics & 34.99 & 7.77 & .05 & -171.36 & .00 & .30 \\
\hline
\end{tabular}

Note: AIC $=$ Akaike information criterion; $\mathrm{DBH}=$ diameter at breast height $(1.3 \mathrm{~m})$. 

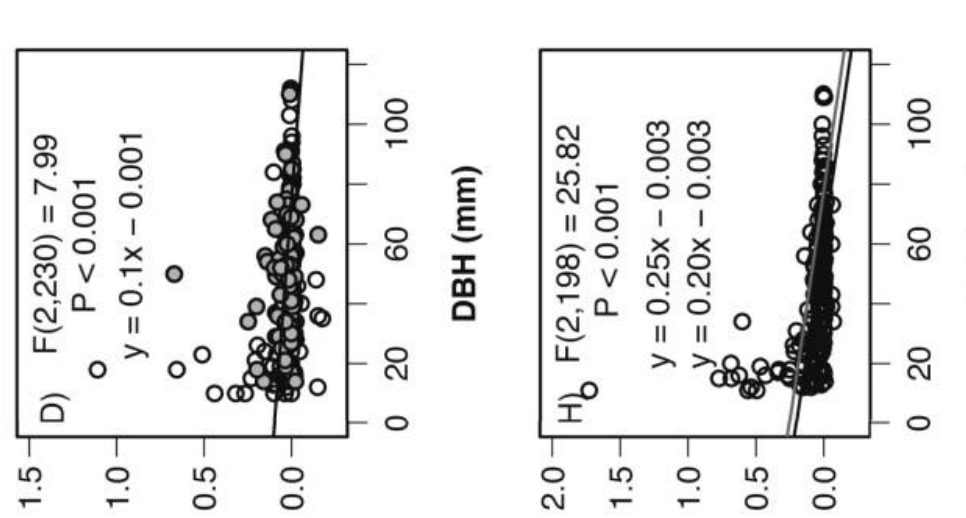

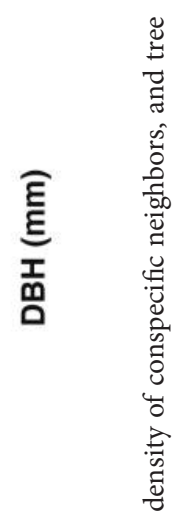
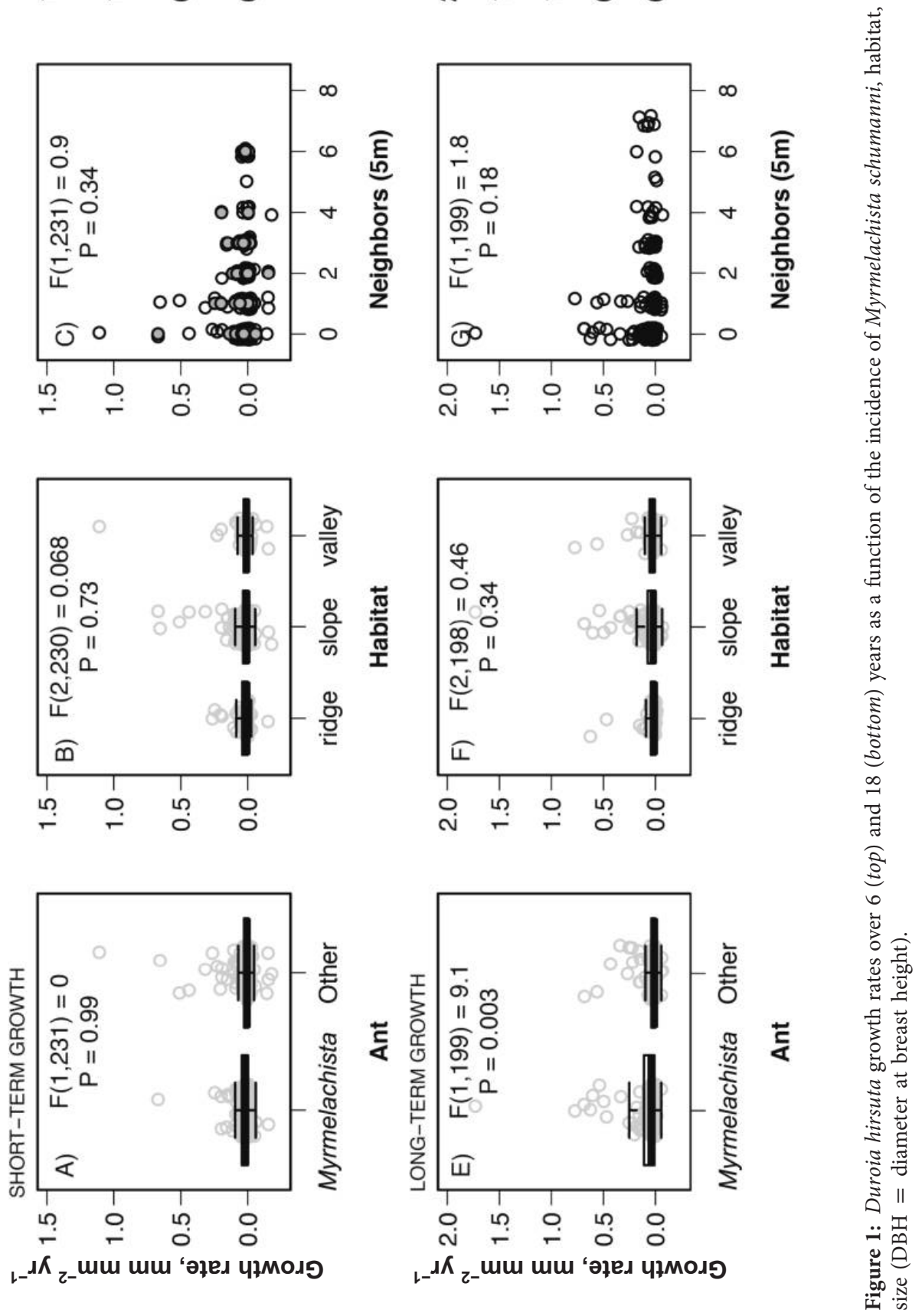

This content downloaded from 128.135.181.207 on August 31, 2016 08:10:36 AM All use subject to University of Chicago Press Terms and Conditions (http://www.journals.uchicago.edu/t-and-c). 
size $\left(R^{2}=0.05\right.$; table 2$)$. Equally valid models included density of conspecifics or habitat, in addition to the interaction ant $\times$ tree size, but added little further explanatory power. Over the long term, the best model included the ant $\times$ tree size $\times$ density of conspecifics interaction and had the greatest explanatory power of all models $\left(R^{2}=30\right)$. Thus, these results suggest that the growth of $D$. hirsuta is defined mainly by the mutualist relation with the ant, tree size, and the density of conspecific neighbors.

We illustrate these relationships with three-dimensional plots for both short- and long-term predicted growth rates as a function of ant incidence, tree initial size, and conspe- cific density (fig. 2). Predicted growth rates were based on the following models: ant $\times$ tree size + density of conspecifics (short term), and ant $\times$ tree size $\times$ density of conspecifics (long term). With zero neighbors, growth rates of D. hirsuta declined with increasing tree initial size (the negative slope parallel with the $X$-axis) whether ants were present or not (fig. 2). Further, with no ants, growth rates of small trees declined with increasing density of conspecific neighbors ( $Y$-axis in fig. $2 B-2 D$ ). However, with ants present, growth rates of small trees were less negative (fig. $2 A, 2 C$ ), counteracting the effects of high conspecific density. The effect of ants on large trees is less clear (right-side $Y$-axis in fig. 2).
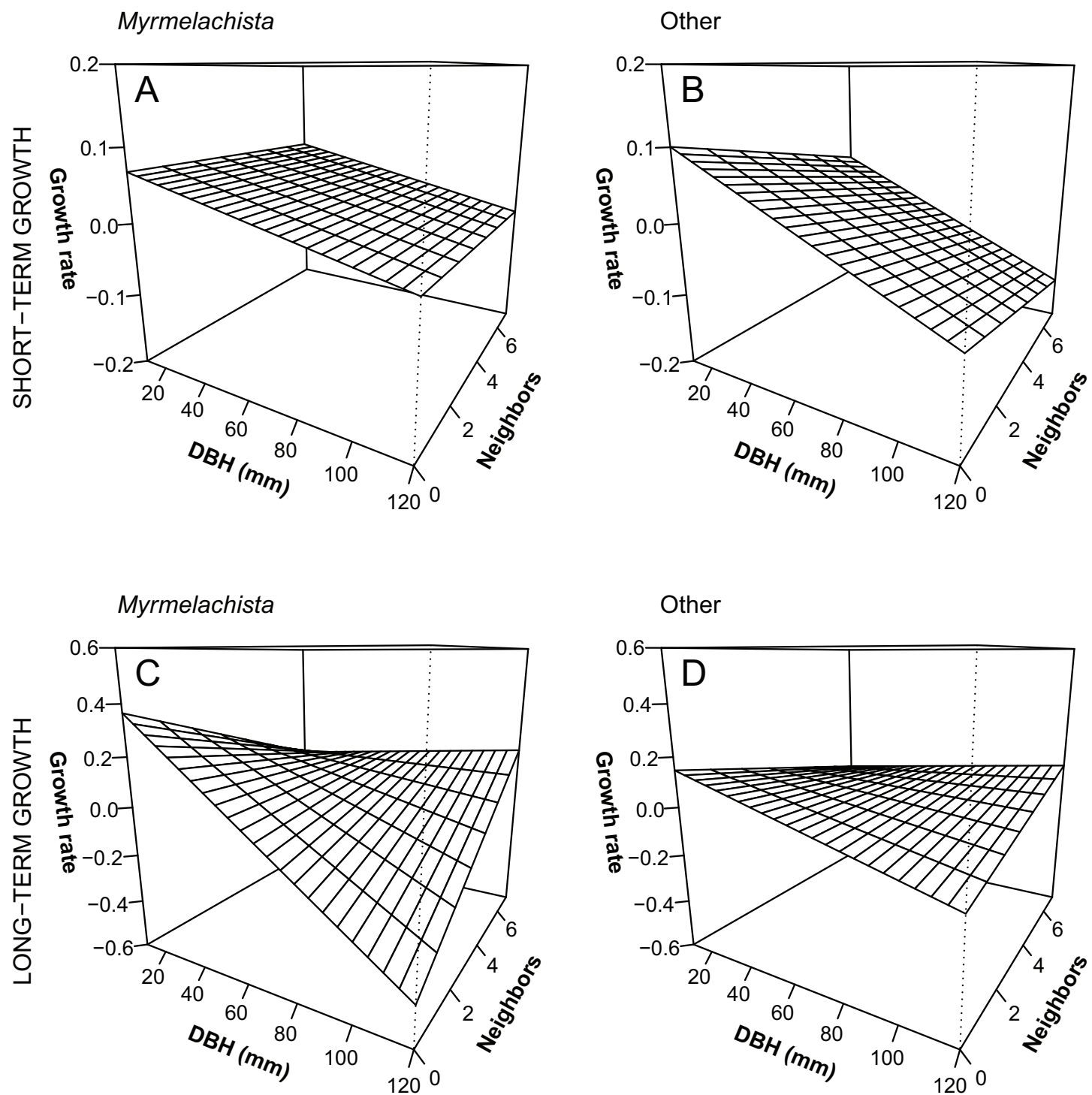

Figure 2: Predicted growth rates of Duroia hirsuta as a function of Myrmelachista schumanni incidence, tree initial size $(\mathrm{DBH}=$ diameter at breast height), and conspecific density. Predicted growth rates are based on the following models: ant $\times$ tree size + density of conspecifics (short term), and ant $\times$ tree size $\times$ density of conspecifics (long term). 
Large trees are less affected by conspecific density and may even grow faster in large groups, although there is some sign that they may be negatively affected by ant presence over the long term when growing with few conspecific neighbors (fig. 2C).

Habitat affected the mutualist relationship only over the short term. On ridges and slopes, tree growth declined with tree size less strongly in trees hosting the ant than in trees without the ant. In valleys, this pattern was reversed (fig. A1, available online).

Survival. Of the 213 trees with documented understory conditions in 2010, 13 died by 2013. Of those trees, three individuals had the mutualistic ant (i.e., were in understory clearings), and 10 did not. Our logistic-regression analysis revealed that $D$. hirsuta in ant clearings had higher probability of survival than those in closed understory (table 3 ). However, D. hirsuta survival was not influenced by tree size, the number of conspecific neighbors surrounding a given tree, or habitat.

\section{Discussion}

The effect of mutualism on plant growth proved to be highly context dependent in our study system. The effect of the mutualist ant on Duroia hirsuta growth rates was shaped by complex interactions between tree ontogeny and population density and, over a short window of time, by variation in habitat. Our results support the idea that the effect of a given mutualist partner may change throughout plant ontogeny (Palmer et al. 2010; see also Dejean et al. 2008, 2015). In consequence, in our study system the mutualist relation plays a critical role in the dynamics of the population of the antplant $D$. hirsuta, a widely distributed tree in the Amazon ba$\sin$.

Indeed, our results did not support the hypothesis that negative density dependence (NDD) intensifies at higher densities of $D$. hirsuta hosting the mutualist ant and proved that NDD was conditional on tree size (or ontogeny), as ant presence counteracted NDD in small ant-plants (and less

Table 3: Survival of Duroia hirsuta over 3 years (2010-2013) as a function of Myrmelachista schumanni presence/absence, tree size, density of conspecifics, and habitat

\begin{tabular}{lccrr}
\hline Term & Estimate & SE & \multicolumn{1}{c}{$\chi^{2}$} & \multicolumn{1}{c}{$P$} \\
\hline Intercept & 1.16 & .84 & 1.84 & .175 \\
Ant presence & 2.82 & .61 & 42.12 & $<.001$ \\
Ant absence & .68 & .49 & 2.11 & .147 \\
Tree size & .01 & .01 & .26 & .619 \\
Density of conspecifics & -.28 & .23 & 1.41 & .246 \\
Slope habitat & -.20 & .41 & .25 & .628 \\
Valley habitat & .38 & .53 & .54 & .461 \\
\hline
\end{tabular}

consistently so in large ones; table 2; fig. 2). Thus, the positive effect afforded by the ant at the scale of individual trees appears to result in improved advantages as the number of trees in a supay chakra rises. For instance, light incidence likely increases disproportionately from the scale of an individual ant-plant to that of an aggregation of several individuals hosting the mutualist ant. In addition, larger ant colonies can be more efficient at protecting ant-plants from herbivory (Anderson and Ratnieks 1999) and perhaps from encroaching vegetation. Further, dispersal limitation of colonies of mutualist ants decreases at higher local densities of ant-plants (Türke et al. 2010), which enhances the rates of colonization and recolonization in unoccupied ant-plants.

It was also unexpected that larger $D$. hirsuta trees had increased growth rates at higher densities of conspecific neighbors when Myrmelachista schumanni was absent (fig. 2). Thus, larger ant-plants probably benefited to a larger extent from the environment of supay chakras when they did not incur the costs of hosting M. schumanni-indeed, large trees with the ant surrounded by few conspecifics had extremely low growth rates (fig. 2). These large plants tended to host other types of mutualist ants (the probability of $D$. hirsuta hosting $M$. schumanni decreases with tree size: $\chi^{2}=5.14, P=.023$, census data of 2013) that probably afforded them other types of benefits, including improved protection from herbivore attack (Koch et al. 2016). This combination of factors likely explains why, in our study site, there is no evidence of higher herbivore pressure in larger supay chakras (Jaramillo 2012).

Over 6 and 18 years, D. hirsuta that hosted M. schumanni grew more than twice as fast as trees without the ant (fig. 1). This figure ranks among the highest records of positive effect of a mutualist ant on plant growth available in the scientific literature, and it is surpassed only by a study showing positive size-dependent growth measured as an increase in the number of domatia in D. hirsuta hosting M. schumanni ants in Peru (Frederickson and Gordon 2009). For example, meta-analyses report that mutualist ants increase plant biomass and leaf production by $25 \%$ and $50 \%$, respectively (Rosumek et al. 2009), and enhance plant growth rates by up to 64\% (Chamberlain and Holland 2009). The effect of growth of M. schumanni on D. hirsuta would be much higher if expressed as rates of domatia production, because the allometry between $\mathrm{DBH}$ growth and domatia production in a tropical myrmecophytic tree ranges around 1.5 (Pringle et al. 2012). The comparison of our models indicated that the long-term positive effect of the mutualist ant on $D$. hirsuta growth results from periods of accelerated growth when the plants host M. schumanni, followed by periods of slow growth when they are vacant or hold other species of mutualist ants. In addition, the positive effect of the ant on plant growth may be enhanced by M. schumanni's tendency to favor fast-growing hosts (Frederickson and Gordon 2009), 
a behavior that is present in other mutualist ants (Palmer et al. 2010).

Contrary to our predictions, the mutualist ant did not enhance the growth of large trees in resource-rich valley habitats, but it had a small positive effect in resource-poorer slopes and ridges only over the short term (table 2; fig. A1). Resource availability across habitats may covary with other factors that modify the net effect of mutualism on ant-plant growth. In particular, higher top-down control on plants and their mutualist ants, generally stronger in more productive habitats (Dyer and Letourneau 2003), may decrease the positive effect of the ant on plant growth. The transient nature of the effect of resource availability on the outcomes of the mutualist relation suggests that dynamic processes are at play (e.g., pulses of productivity, herbivore satiation) and that they average out in the long run.

In our study system, $M$. schumanni was a critical determinant of survival of the ant-plant (table 3 ), although this result should be taken carefully because of the small number of individuals that died between the two ant censuses. Higher odds of survival of D. hirsuta hosting M. schumanni have been shown at a Peruvian site and are related to larger tree size and higher growth rates (Frederickson and Gordon 2009). Here, however, tree size did not enhance the probability of survival of the ant-plant, which differs from the survival patterns of the tree community in the whole permanent plot (Valencia et al. 2009). Possibly, the lack of size-dependent mortality in our study is due to large-scale tree population dynamics (Chisholm et al. 2014), which may also explain the lack of effect of habitat and density of conspecifics on the odds of survival of D. hirsuta. Indeed, at our site the D. hirsuta population has decreased by almost $20 \%$ since 1995 , but we could not document the effects of ants on this large-scale mortality because the first ant census was in 2010.

Our findings offer insights into the mechanisms involved in the population dynamics of D. hirsuta. During the establishment of a supay chakra, the interaction between $D$. hirsuta and $M$. schumanni appears critical to enhance the growth rates and decrease the effects of NDD among small, young ant-plants. Once the supay chakra is established, the positive effect of the mutualist ant remains important to smaller ant-plants, as large plants perform better without this mutualist partner when surrounded by high density of conspecifics. Supay chakras may come to an end when they are dominated by larger ant-plants that do not host $M$. schumanni; in this case, dispersal limitation and NDD may also prevent smaller plants from interacting with M. schumanni, which would interfere with the process of recruitment of new individuals into the supay chakra. These patterns could be uncovered only with long-term data gathered over large spatial scales. Studies exploring the effects of interspecific interactions on the dynamics of plant populations may shed light on the mechanisms that govern spatial variation of species diversity in highly diverse tropical forests.

\section{Acknowledgments}

This study greatly benefited from the insightful comments and suggestions provided by M. Frederickson, M. Trager, and two anonymous reviewers. S. Báez acknowledges the financial support of the National Geographic Society (grant 8490-08) and the Secretaría de Educación Superior, Ciencia, Tecnología e Innovación (SENESCYT)-Ecuador for a Prometeo Fellowship. D. A. Donoso thanks W. Carson for discussions on Barro Colorado Island. P. Alvia, A. Loor, and R. Ricart provided invaluable field assistance. R. Valencia thanks the Pontificia Universidad Católica del Ecuador (PUCE) and the Smithsonian Tropical Research Institute for continuous support. The Yasuní 50-ha forest dynamics plot has received support from various funds and institutions since 1995. This work was done under Ministerio del Ambiente research permits 013-2013-FAU-MAE-DPAOPNY, 004-2014-FAU-MAE-DPAO-PNY，002-2012-IC-FLOMAE-DPO-PNY, and 002-2015-IC-FLO-PNY-DPAO.

\section{Literature Cited}

Anderson, C., and F. L. W. Ratnieks. 1999. Task partitioning in insect societies. I. Effect of colony size on queueing delay and colony ergonomic efficiency. American Naturalist 154:521-535.

Báez, S., D. A. Donoso, S. A. Queenborough, L. Jaramillo, R. Valencia, and O. Dangles. 2016. Data from: Ant mutualism increases long-term growth and survival of a common Amazonian tree. American Naturalist, Dryad Digital Repository, http://dx.doi.org/10.5061/dryad $.42 \mathrm{p} 15$.

Bass, M. S., M. Finer, C. N. Jenkins, H. Kreft, D. F. Cisneros-Heredia, S. F. McCracken, N. C. A. Pitman, et al. 2010. Global conservation significance of Ecuador's Yasuní National Park. PLoS ONE 5(1): e8767. doi:10.1371/journal.pone.0008767.

Boege, K., and R. J. Marquis. 2005. Facing herbivory as you grow up: the ontogeny of resistance in plants. Trends in Ecology and Evolution 20:441-448.

Bronstein, J. L. 1994. Conditional outcomes in mutualistic interactions. Trends in Ecology and Evolution 9:214-217.

Bronstein, J. L., R. Alarcón, and M. Geber. 2006. The evolution of plant-insect mutualisms. New Phytologist 172:412-428.

Burnham, K. P., and D. R. Anderson. 2004. Multimodel inference: understanding AIC and BIC in model selection. Sociological Methods and Research 33:261-304.

Chamberlain, S. A., and N. Holland. 2009. Quantitative synthesis of context dependency in ant-plant protection mutualisms. Ecology 90:2384-2392.

Chisholm, R. A., R. Condit, K. A. Rahman, P. J. Baker, S. Bunyavejchewin, Y.-Y. Chen, G. Chuyong, et al. 2014. Temporal variability of forest communities: empirical estimates of population change in 4000 tree species. Ecology Letters 17:855-865.

Comita, L. S., S. A. Queenborough, S. J. Murphy, J. L. Eck, K. Xu, M. Krishnadas, N. Beckman, and Y. Zhu. 2014. Testing predictions of 
the Janzen-Connell hypothesis: a meta-analysis of experimental evidence for distance- and density-dependent seed and seedling survival. Journal of Ecology 102:845-856.

Dejean, A., F. Azémar, R. Céréghino, M. Leponce, B. Corbara, J. Orivel, and A. Compin. 2015. The dynamics of ant mosaics in tropical rainforests characterized using the Self-Organizing Map algorithm. Insect Science 23:630-637. doi:10.1111/1744-7917.12208.

Dejean, A., C. Djiéto-Lordon, R. Céréghino, and M. Leponce. 2008. Ontogenetic succession and the ant mosaic: an empirical approach using pioneer trees. Basic and Applied Ecology 9:316-323.

Dyer, L. A., and D. K. Letourneau. 2003. Top-down and bottom-up diversity cascades in detrital vs. living food webs. Ecology Letters 6:60-68.

Edwards, D. P., M. E. Frederickson, G. H. Shepard, and D. W. Yu. 2009. A plant needs ants like a dog needs fleas: Myrmelachista schumanni ants gall many tree species to create housing. American Naturalist 174:734-740.

Folgarait, P. J., and D. W. Davidson. 1995. Myrmecophytic Cecropia: antiherbivore defenses under different nutrient treatments. Oecologia (Berlin) 104:189-206.

Frederickson, M. E. 2005a. Ant species confer different partner benefits on two Neotropical myrmecophytes. Oecologia (Berlin) 143:387-395.

. 2005b. Devil's garden's bedevilled by ants. Nature 437:495-496.

Frederickson, M. E., and D. M. Gordon. 2007. The devil to pay: a cost of mutualism with Myrmelachista schumanni ants in 'devil's gardens is increased herbivory on Duroia hirsuta trees. Proceedings of the Roval Societv B: Biological Sciences 274:1117-1123.

- 2009. The intertwined population biology of two Amazonian myrmecophytes and their symbiotic ants. Ecology 90:15951607.

Frederickson, M. E., A. Ravenscraft, G. A. Miller, L. M. Arcila Hernández, G. Booth, and N. E. Pierce. 2012. The direct and ecological costs of an ant-plant symbiosis. American Naturalist 179:768 778.

Heil, M., A. Hilpert, B. Fiala, R. Bin Hashim, E. Strohm, G. Zotz, and K. E. Linsenmair. 2002. Nutrient allocation of Macaranga triloba ant plants to growth, photosynthesis and indirect defence. Functional Ecology 16:475-483.

Jaramillo, L. 2012. Mutualismo entre las hormigas Myrmelachista sp. (Hymenoptera: Formicidae) y Duroia hirsuta (Rubiaceae) en el bosque del Yasuní: efecto sobre la agregación de los árboles y la herbivoría por insectos. Licenciate diss. Pontificia Universidad Católica del Ecuador, Quito, Ecuador.

John, R., J. W. Dalling, K. E. Harms, J. B. Yavitt, R. F. Stallard, M. Mirabello, S. P. Hubbell, et al. 2007. Soil nutrients influence spatial distributions of tropical tree species. Proceedings of the National Academy of Sciences of the USA 104:864-869.

Kersch, M. F., and C. R. Fonseca. 2005. Abiotic factors and the conditional outcome of an ant-plant mutualism. Ecology 86:2117-2126.

Koch, E. B. A., F. Camarota, and H. L. Vasconcelos. 2016. Plant ontogeny as a conditionality factor in the protective effect of ants on a Neotropical tree. Biotropica 48:198-205.

Lange, D., and K. Del-Claro. 2014. Ant-plant interaction in a tropical savanna: may the network structure vary over time and influence on the outcomes of associations? PLoS One 9:e105574. doi:10.1371 /journal.pone.0105574.

Losos, E. C., and G. L. Egbert, Jr. 2004. Tropical forest diversity and dynamism: findings from a large-scale plot network. University of Chicago Press, Chicago.
Mayer, V. E., M. E. Frederickson, D. McKey, and R. Blatrix. 2014. Current issues in the evolutionary ecology of ant-plant symbioses. New Phytologist 202:749-764.

Miller, T. E. X., and V. H. W. Rudolf. 2011. Thinking inside the box: community-level consequences of stage-structured populations. Trends in Ecology and Evolution 26:457-466.

Palmer, T. M., D. F. Doak, M. L. Stanton, J. L. Bronstein, E. T. Kiers, T. P. Young, J. R. Goheen, and R. M. Pringle. 2010. Synergy of multiple partners, including freeloaders, increases host fitness in a multispecies mutualism. Proceedings of the National Academv of Sciences of the USA 107:17234-17239.

Pérez, Á. J., C. Hernández, H. Romero-Saltos, and R. Valencia. 2014 Árboles emblemáticos de Yasuní. Publicaciones del Herbario QCA. Quito, Pontificia Universidad Católica del Ecuador.

Pringle, E. G., R. Dirzo, and D. M. Gordon. 2012. Plant defense, herbivory, and the growth of Cordia alliodora trees and their symbiotic Azteca ant colonies. Oecologia (Berlin) 170:677-685.

Queenborough, S. A., D. F. R. P. Burslem, N. C. Garwood, and R. Valencia. 2007. Habitat niche partitioning by 16 species of Myristicaceae in Amazonian Ecuador. Plant Ecology 192:193-207.

R Development Core Team. 2014. R: a language and environment for statistical computing. Version 2.8.1. R Foundation for Statistical Computing, Vienna, Austria.

Rosumek, F. B., F. A. O. Silveira, F. de S. Neves, N. P. de U. Barbosa, L. Diniz, Y. Oki, F. Pezzini, G. W. Fernandes, and T. Cornelisson. 2009. Ants on plants: a meta-analysis of the role of ants as plant biotic defenses. Oecologia (Berlin) 160:537-549.

SAS Institute. 2008. JMP. Version 9. SAS Institute, Cary, NC

Stanton, M. L., and T. M. Palmer. 2011. The high cost of mutualism: effects of four species of East African ant symbionts on their myrmecophyte host tree. Ecology 92:1073-1082.

Symonds, M. E., and A. Moussalli. 2011. A brief guide to model selection, multimodel inference and model averaging in behavioural ecology using Akaike's information criterion. Behavioral Ecology and Sociobiology 65:13-21.

Trager, M. D., S. Bhotika, J. A. Hostetler, G. V. Andrade, M. A. Rodriguez-Cabal, C. S. McKeon, C. W. Osenberg, and B. M. Bolker. 2010. Benefits for plants in ant-plant protective mutualisms: a meta-analysis. PLoS One 5:e14308. doi:10.1371/journal.pone.0014308.

Tuomisto, H., A. D. Poulsen, K. Ruokolainen, R. C. Moran, C. Quintana, and G. Canas. 2003. Linking floristic patterns with soil heterogeneity and satellite imagery in Ecuadorian Amazonia. Ecological Applications 13:352-371.

Türke, M., B. Fiala, K. E. Linsenmair, and H. Feldhaar. 2010. Estimation of dispersal distances of the obligately plant-associated ant $\mathrm{Cre}$ matogaster decamera. Ecological Entomology 35:662-671.

Valencia, R., R. Condit, H. C. Muller-Landau, C. Hernandez, and H. Navarrete. 2009. Dissecting biomass dynamics in a large Amazonian forest plot. Journal of Tropical Ecology 25:473-482.

Valencia, R., R. B. Foster, G. Villa, R. Condit, J.-C. Svenning, C. Hernández, K. Romoleroux, E. Losos, E. Magård, and H. Balslev. 2004. Tree species distributions and local habitat variation in the Amazon: large forest plot in eastern Ecuador. Iournal of Ecology 92:214229.

Wright, S. J. 2002. Plant diversity in tropical forests: a review of mechanisms of species coexistence. Oecologia (Berlin) 130:1-14.

Natural History Editor: Mark A. McPeek 